\title{
0 CARNAVAL CARIOCA E A CONSTRUÇÃO DE UMA IDENTIDADE BRASILEIRA
}

Renata Bulcão (UFRJ)

As mudanças ocorridas no carnaval brasileiro no recorte de 100 anos que este artigo abarca são exemplos práticos dos movimentos da história intelectual latino-americana desse período. Da busca de referências europeias ao esforço de "forjar" uma identidade nacional própria, os intelectuais brasileiros usarão sua influência em diversas áreas, entre elas a folia.

CARNAVAL, HISTÓRIA INTELECTUAL, IDENTIDADE NACIONAL.

BULCÃO, Renata. O carnaval carioca e a construção de uma identidade brasileira. Textos escolhidos de cultura e arte populares, Rio de Janeiro, v.8, n.2, p. 143-153, nov. 2011. 
A história intelectual é campo historiográfico que se propõe a estudar as mentalidades, a produção e circulação de ideias e conceitos. Tem como foco, portanto, o estudo dos intelectuais de diversos períodos, incluindo escritores, romancistas, folcloristas, diplomatas, professores, enfim, personagens que tenham contribuído de alguma maneira para a formação de um campo de ideias hegemônicas em dado período.

Essa vertente pode ser aplicada ao estudo das mais diversas áreas, e é isso que pretendemos fazer neste trabalho. A fim de entender as mudanças e tensões pelas quais o carnaval carioca passou ao longo das décadas desde o século XIX, buscamos atingir uma mentalidade hegemônica, que era defendida pela elite intelectual do continente e que definiu os rumos da folia. É importante levar em conta, no entanto, que os projetos formulados por essa intelectualidade nem sempre produziram os resultados desejados, visto que, ao entrar em contato com a realidade, sofreram modificações e ressignificações. Sua presença, entretanto, alteraria os rumos, ainda que de maneira nem sempre possível de controlar.

Ao nos debruçarmos sobre a história intelectual podemos perceber diversos movimentos e tendências que indicam distintos locais, momentos e correntes de pensamento. A análise desses movimentos é relevante posto que eles influenciam ações concretas dos intelectuais com relação à sociedade em que vivem. É via de mão dupla: os acontecimentos que rodeiam os intelectuais contribuem para a formação de novas correntes de pensamento, assim como essas correntes se refletem na dinâmica que esses intelectuais tentam imprimir na sociedade. Jornalistas, estadistas, diplomatas, folcloristas se empenham no esforço de "moldar" a realidade, alguns obtendo mais sucesso do que outros. Dessa maneira, medidas tomadas por um Estado em determinado momento, por exemplo, não devem ser vistas como aleatórias, mas como partes integrantes de correntes intelectuais vigentes no período.

Isso é perceptível no caso do carnaval brasileiro e de suas mudanças desde o século XIX. As mudanças de perspectiva com relação à folia nesse recorte de 100 anos são reflexo das concomitantes alterações de paradigma da intelectualidade brasileira e latino-americana. O modo como jornalistas e estadistas buscaram "inventar" o carnaval por meio de atos governamentais e propagandas na imprensa condiz com as correntes ideológicas predominantes em cada momento, que ditavam como deveria ser a "civilização" ideal.

A virada do século XIX para o XX, especialmente, foi período agitado na história intelectual latino-americana. Nas relações internacionais, os imperialismos europeu e norte-americano se faziam extremamente presentes, trazendo à tona o binômio "civilização X barbárie", que legitimava a dominação dos países ricos sobre os pobres: o velho continente era o símbolo do progresso e, por esse motivo, deveria ser responsável por expandi-lo para a América. Os países americanos, "bárbaros", portanto, poderiam livrarse de seu atraso se aceitassem os costumes e a política europeia, construindo um futuro, "civilizado". 
A América Latina do século XIX viu a configuração de seus Estados nacionais, que foram construídos de maneira invertida: os Estados americanos não surgiram de um sentimento comum de pertencimento - de nacionalidade -, mas de questões puramente políticas. Dessa maneira, coube aos intelectuais desses "Estados artificiais" forjar uma identidade nacional que pudesse unificar práticas e ideias, e transformar seus países em verdadeiras nações. Influenciados pela base do pensamento hegemônico europeu (que, como já explicitado, classificava os povos em "civilizados" ou "bárbaros"), entretanto, esses pensadores americanos identificavam seu continente como atrasado e percebiam que seus projetos nacionais - e continentais - deveriam contemplar um esforço em busca do progresso. Nesse sentido, a ideologia da civilização e do progresso foi amplamente utilizada, uma vez que era preciso "inventar" nações novas, civilizadas. A América tornava-se o continente do porvir; com passado colonial ligado ao barbarismo, trabalhava para alcançar o progresso. Passado e presente vergonhosos caminhariam para um futuro glorioso, já que os intelectuais estariam construindo novas nações.

Esses "Estados artificiais", no entanto, tornavam-se ainda mais difíceis de ser forjados, já que o ideal de civilização não condizia com a realidade americana. O principal empecilho, que afastava os povos europeus daqueles do Novo Mundo, era a questão da raça: como seria possível, em países com imenso contingente de negros e mestiços, a criação de nações civilizadas, comparáveis às europeias? O peruano Francisco García Calderón afirmava que "a raça era a chave para explicar a incurável desordem que divide a América Latina" (HALE, p. 368). No Brasil, esse dilema tomou proporções ainda maiores, sendo agravado por conta da recente abolição da escravatura. Haveria, na nova nação, espaço para os ex-escravos que, agora, engrossavam as fileiras de negros livres? As visíveis diferenças físicas e culturais entre os povos latino-americanos mestiços e europeus brancos faziam com que os intelectuais buscassem remédios para esse evidente "atraso" americano.

A solução foi encontrada na adaptação das teorias spencerianas do "darwinismo social". Filósofo inglês muito influente nesse momento, Herbert Spencer criou teorias baseadas na evolução natural de Darwin, adaptando-a para o campo da sociologia. Em seu entendimento, existiriam grupos humanos superiores a outros, o que poderia ser percebido por meio da análise de características biológicas e sociais. Uma dessas características seria a raça: os caucasianos, segundo Spencer, seriam mais aptos e desenvolvidos do que os negros e mestiços. A teoria spenceriana envolve diversas outras questões, mas foi sua ideia sobre a raça que mais interessou os intelectuais americanos de finais do Oitocentos.

O racismo científico foi imediatamente abraçado pelas elites da virada do século, que enfrentavam o desafio de como transformar suas nações 'atrasadas' e subdesenvolvidas em repúblicas modernas e 'civilizadas'. Essa transformação, concluíram elas, teria de ser mais do que apenas política ou econômica; teria de ser também racial. Para ser civilizada, a América Latina teria de se tornar branca (ANDREW, p. 152). 
Contaminados, portanto, pelas teorias raciais de caráter biológico, os intelectuais americanos se empenharam na criação de diversos projetos que tinham como objetivo o "embranquecimento" das populações do continente, ou seja, a eugenia. Dessa maneira, não é difícil encontrarem-se discursos desse período defendendo a vinda em massa de imigrantes europeus para a América e até cálculos matemáticos que buscavam definir quantas gerações de imigrantes seriam necessárias para tornar as populações americanas verdadeiramente brancas.

Os projetos de eugenia, no entanto, não visavam apenas ao embranquecimento da cor da pele. A questão era mais ampla; envolvia tradições culturais. Na verdade, esses intelectuais identificavam como símbolos da barbárie aspectos culturais comuns aos povos negros e mestiços, e que já estavam disseminados no continente. Os ritmos musicais, as danças e as práticas religiosas eram as principais vítimas dessa depreciação. No Brasil, essas disputas vão acontecer com a mesma intensidade, e o carnaval será um dos principais focos desse embate.

Até o século XIX, a folia brasileira era baseada no costume do entrudo. Trazido de Portugal, esse modo de festejar os dias anteriores à Quaresma era marcado pela anarquia e, às vezes, até pela violência. Da festa participavam pessoas de todas as camadas sociais, ainda que de maneiras diferentes: o entrudo familiar era uma prática das elites brasileiras, realizado dentro das casas entre parentes e amigos, sendo vetada a participação dos escravos. O entrudo popular, por outro lado, era feito principalmente por essas camadas mais baixas excluídas da festa das elites e, portanto, tomavam conta das ruas empreendendo molhadelas e enfarinhamentos aos passantes. Os negros escravos, se aproveitando dessa atmosfera, entregavam-se ao entrudo popular, ocupando as ruas também com suas próprias manifestações: eram comuns procissões com música e dança, chamadas cucumbis.

Com as mudanças de paradigma da história intelectual já mencionadas, esses costumes começam a ser condenados. $O$ entrudo (principalmente o popular) era manifestação associada a camadas populares, negras e mestiças e, portanto, motivo de "atraso" nacional. Além disso, a partir de 1822, tudo o que tinha origem portuguesa passa a ser considerado ultrapassado, já que, recém-independente, era preciso que o Brasil se distanciasse das tradições portuguesas, traçando seu próprio caminho. Em oposição, países como a França e a Itália surgem como referências alternativas, representantes de modernidade que deveria ser almejada, ou seja, o "modelo civilizatório" europeu será sintetizado, nesse momento, nas referências italianas e, principalmente, francesas, afastandose das lusitanas.

O combate ao entrudo deu-se de diversas maneiras, contando com ações incisivas do Estado. A venda de limões de cheiro (pequenas bolas feitas de cera que continham líquidos aromatizados e eram largamente utilizadas nas molhadelas do entrudo) chegou a ser proibida por lei, mas não pôde ser reprimida com tanta facilidade. ${ }^{1}$ As ações do Estado buscaram apoio também no discurso cientificista higienista. Até mesmo 
a Inspetoria de Higiene iria lutar contra as práticas entrudísticas, como percebemos neste comunicado:

A inspetoria geral de higiene aconselha aos habitantes desta capital que se abstenham do jogo do entrudo, divertimento bárbaro, impróprio de uma nação civilizada e que só males produz aos que a ele se entregam (...) Se todos aceitarem este conselho higiênico, se os chefes de família se empanharem nesta cruzada de civilização e de progresso, muitas vidas serão poupadas e as autoridades ficaram dispensadas de fazer cumprir as determinações da postura municipal, que proíbe tão prejudicial passatempo (Gazeta de Noticias, 7 de março de 1886).

Nesse sentido, o entrudo e a possibilidade de descontrole que ele representava começam a ser motivo de preocupação de intelectuais e membros da elite que, portanto, passam a buscar manifestação que pudesse substituir a festa. O primeiro modelo dessa tentativa seriam os bailes de máscaras.

Inspirados nos bals maqués franceses, os bailes começam a surgir no Brasil na década de 1830 e representavam tudo o que se opõe ao entrudo: elegância, formalização, ostentação. Sua dinâmica impedia a participação popular, já que, além de cobrarem ingressos a altos preços, os organizadores exigiam referências que provassem que o participante era oriundo de uma "boa família". Podemos perceber nos periódicos desse período, pela primeira vez, a utilização do termo "carnaval" em oposição a "entrudo". Essa oposição seria uma variação do binômio "civilização e barbárie": o carnaval luxuoso dos mascarados franceses era a representação da modernidade, que deveria substituir o atraso e a desorganização do entrudo lusitano.

Seguindo esse movimento, começam a surgir no mesmo período as sociedades carnavalescas, que não passavam de clubes em que se reuniam membros da elite interessados em brincar o carnaval dos bailes. Os associados costumavam reunir-se nas sedes de suas sociedades para vestir as fantasias e ir juntos, em cortejo, até o local dos bailes, como meio de expor sua elegância e riqueza para quem os visse nas ruas. A primeira sociedade a se destacar foi o Congresso das Summidades Carnavalescas:

À meia noite foi servida, no grande salão da quarta ordem, a ceia do Congresso das Summidades Carnavalescas. Além de todos os sócios ricamente fantasiados, estiveram presentes muitas famílias respeitáveis e pessoas de distinção. Entre outras saúdes fizeram-se as seguintes: - Ao progresso, à civilização, à abolição do entrudo antigo (...) (Correio Mercantil, 22 de fevereiro de 1855).

Entretanto, é importante ressaltar que nem tudo funcionava como o esperado. Pelo contrário, em vez de combater a anarquia do entrudo, os bailes de máscaras acabaram por intensificá-la em alguma medida: as classes mais baixas passaram a tentar imitar os costumes das elites, copiar suas máscaras e fantasias, e utilizá-las nas ruas, sem aban-

BULCÃO, Renata. O carnaval carioca e a construção de uma identidade brasileira 
donar as brincadeiras grosseiras a que estavam acostumados. $O$ uso das máscaras incentivava excessos, e crimes passaram a ocorrer com mais intensidade no período que antecede a Quaresma. Os "máscaras" dos cortejos das grandes sociedades muitas vezes eram novos alvos dos objetos e líquidos que tomavam conta das ruas no entrudo.

O plano de "educar" a população para transformar sua festa em civilizada não funcionou, principalmente porque os bailes não substituíram o entrudo e sim passaram a, simplesmente, conviver com ele. Era preciso tomar o espaço do entrudo nas ruas, de modo que a população pudesse participar da nova brincadeira e, portanto, abandonar suas manifestações "grosseiras". O modo encontrado para isso foi a multiplicação dos cortejos das grandes sociedades, que passaram a se chamar "préstitos".

Como mencionado, o costume dos cortejos carnavalescos já estava consolidado. O que ocorreu a partir de 1855 foi a multiplicação desses cortejos, que deixaram de ser apenas meio de se chegar aos bailes e passaram a ser passeios que se bastavam. Sobre um desses préstitos, o Correio Mercantil publicou: “O seu passeio hoje à tarde pelas ruas da cidade promete ser um belo espetáculo, o mais belo por certo desde que entre nós se introduziu novamente o costume das mascaradas." O texto do Correio Mercantil é do escritor José de Alencar, famoso romancista e folclorista, e um dos fundadores do Congresso das Summidades Carnavalescas. Alencar é exemplo dos inúmeros intelectuais que apoiavam fervorosamente o projeto do "Carnaval civilizado", empreendido pelas grandes sociedades.

2. Apesar da participação nas ações antientrudo, o Estado não costumava dar apoio explícito às sociedades carnavalescas. A organização das festas e dos préstitos era encargo dos próprios diretores e participantes, pertencentes à elite econômica e intelectual.

3. "Crônica carnavales$c a$ ", Gazeta de Notícias, 10/02/1893.
As sociedades carnavalescas (que já haviam então também se multiplicado) organizavam seus passeios por conta própria, sem qualquer interferência estatal no sentido de organizar esses préstitos. ${ }^{2}$ Era comum que cada uma fizesse pelo menos dois desfiles por ano: o primeiro no domingo de carnaval (préstito burlesco) com alegorias de crítica, contando com o apoio fervoroso de importantes abolicionistas e intelectuais; o segundo na terça-feira (préstito de gala) e seu único propósito era a ostentação da riqueza das elites. Evidenciam-se, assim, os dois principais objetivos das sociedades carnavalescas: a educação do "populacho" e a ostentação.

Nos préstitos carnavalescos, portanto, a presença da plateia era essencial, e a construção de pequenos carros alegóricos servia ao objetivo de impressionar e fazer da população espectadores passivos daquele "exemplo de civilidade". Buscava-se impor uma imagem de festa unificada, ou seja, de uma festa que pudesse ser de todos, mesmo que para isso fosse negada às grandes massas a participação efetiva na brincadeira. A Gazeta de Notícias chegou a publicar a seguinte frase: "O carnaval entrou na cidade como um conquistador." ${ }^{3}$ Fazendo analogia com o processo de colonização, o periódico expressava o desejo das elites de impor os valores europeus e "civilizados" à realidade brasileira. 
As sociedades conseguiram o sucesso almejado, tornando-se o grande evento do carnaval carioca. Diferente do que pretendiam seus criadores, entretanto, a população não permaneceu passiva; pelo contrário, buscou participar da festa de todas as maneiras possíveis: acompanhando os préstitos, enfeitando as ruas e até criando suas próprias sociedades (já nos últimos anos do século XIX, começam a surgir sociedades suburbanas, comandadas por pequenos comerciantes em busca de prestígio). Essa popularização dos préstitos fez com que fossem contaminados pelas formas populares

4. Testamento do Carnaval", Semana llustrada, $07 / 02 / 1875$. de brincar, havendo miscigenação tão grande, que não se podia mais distinguir tão facilmente o entrudo e o carnaval. A Semana llustrada chega a anunciar a "morte" do carnaval, ${ }^{4}$ que teria perdido suas características, misturando-se com o entrudo.

Seis anos depois, publica-se manifesto assinado pelas três principais sociedades cariocas (Tenentes do Diabo, Democráticos e Fenianos):

Inaugurado o carnaval nesta corte, há longos anos (...) o seu aparecimento foi acolhido com geral agrado pela população fluminense, que nesse folguedo viu, com justeza e discernimento, uma prova de progresso e civilização, e que (...) baniu de seus antigos hábitos, como nocivo, como anacrônico, como impróprio da sociedade moderna e da civilização adiantada a que tem atingido, o bárbaro divertimento do entrudo (...) Entretanto, de há dois anos para cá, o entrudo começou a ressurgir, e, avançando gradativamente, ameaça este ano tomar proporções assustadoras. O seu restabelecimento será o aniquilamento completo do carnaval, isto é, o atraso em vez do progresso, a treva em lugar da luz, a morte substituindo a vida (...) Seria incontestavelmente doloroso que esses dispêndios, que estes sacrifícios, que estes esforços fossem mal compreendidos e tivessem imerecido acolhimento, sendo assim suplantado o carnaval, que representa a civilização, pelo entrudo, que representa o barbarismo! (Jornal do Commercio, 25 de fevereiro de 1881).

É importante ressaltar que o entrudo nunca desapareceu por completo das ruas cariocas. Ele sempre conviveu tanto com os bailes de máscaras quanto com os préstitos das sociedades. O que incomoda os autores do manifesto, entretanto, é a influência que as brincadeiras populares começaram a ter no carnaval, ou seja, a perda da exclusividade das grandes sociedades, a diminuição de seu espaço físico e simbólico, e a adoção desse tipo de brincadeira pelas massas populares e classes médias. Essa miscigenação entre diversos tipos de manifestações iria resultar no surgimento de diferentes grupos que, já na década de 1920, seriam denominados "ranchos", "blocos" e "cordões".

O manifesto das grandes sociedades é, portanto, exemplo claro da relação entre o carnaval e a história intelectual: como já dito, esse período do final do século XIX foi momento delicado para os intelectuais latino-americanos, que se viram imbuídos do desejo de "forjar" uma identidade civilizada para seus países. O esforço em liquidar o entrudo e substituí-lo pelo carnaval de influência europeia faz parte, portanto, desse projeto nacional brasileiro, e o manifesto citado exprime com clareza esse caráter eurocêntrico. 
A questão da raça, portanto, tornou-se empecilho no projeto "europeizante" desses grupos da elite intelectual. Era necessário diminuir as diferenças físicas e culturais entre Europa e América (ligadas a tradições brancas, de um lado, e mestiças, de outro). 0 desafio de elaborar projetos nacionais que incluíssem os não brancos acabou se dando, entretanto, de forma apenas teórica, não existindo nenhuma política efetiva de inclusão desses grupos no período de passagem do século XIX para o XX, configurando um hiato entre a realidade e a visão da elite branca. Os préstitos são exemplo disso: tinham a pretensão de um carnaval unificado, mas, na verdade, reservavam à população (negra e mestiça) papel passivo.

Esse cenário de desvalorização da contribuição e tradição negra e mestiça, contudo, vai-se modificar já na década de 1920. A Primeira Guerra Mundial e a ascensão do nazifascismo geram crise que vai atingir a América: o modelo europeu já não parecia mais funcionar, pois havia gerado uma guerra de grandes proporções. Além disso, as teorias racistas começam a entrar em crise por conta do nazifascismo, que as levava ao extremo, mostrando resultados devastadores. Os intelectuais latino-americanos voltamse, então, para suas próprias realidades, procurando resgatar as características próprias do continente americano e construir identidade que se adequasse à realidade desses países. O mimetismo com relação à Europa dá lugar ao desejo de adaptação das teorias políticas e culturais para a realidade americana. A mestiçagem passa a ser valorizada, e conceitos como "hibridização" e "transculturação" ganham força.

O maior nome dessa nova fase das teorias raciais foi, sem dúvidas, o mexicano José Vasconcelos. Em seu livro La raza cósmica, defende a posição de que a América estaria à frente no processo evolutivo que levaria a uma quinta raça -“la quinta raza, que ha de producirse en América" (VASCONCELOS, 1925). A quinta raça (melhor e mais aprimorada do que as demais) seria resultado da miscigenação de todas as outras, e o latinoamericanismo, portanto, seria a síntese dessa fusão racial. "A concepção mexicana de nacionalidade rompia com as noções de europeicidade e brancura" (GERSTLE, 2008, p. 424).

Outros países latino-americanos também viram seus intelectuais seguirem esse caminho de valorização da mestiçagem e das manifestações populares. O Brasil foi um deles, e esse novo paradigma se viu refletido no carnaval e no modo como passou a ser tratado. $O$ texto publicado pelo escritor Berilo Neves em 1932 explicita bem o que referimos:

O Carnaval carioca não é uma farra anônima e sim, uma expressão do gênio da Raça e, como tal tem que continuar espontâneo e livre para que continue a existir. Cada povo tem uma certa festa ou manifestação de arte da qual respira e vive (...) Tirem-nos essas manifestações de sentimento e ficaremos, talvez, completamente despersonalizados. Porque ou imitemos a França (na literatura sobretudo) ou copiemos os Estados Unidos (principalmente depois do cinema), o fato é que estamos sempre macaqueando alguém ou alguma coisa. Só o carnaval é privativamente nosso, irrevogavelmente nosso (...) Ora, um povo que cria alguma coisa de próprio e inconfundível é um povo que tem grandes qualidades para vencer... (Diário de Notícias, 4 de fevereiro de 1932). 
Berilo Neves e muitos outros intelectuais brasileiros começavam a perceber o caráter popular do carnaval carioca como sinônimo de nacionalidade, capaz de criar uma identidade cultural para o país.

Esse novo olhar sobre a folia se refletiu nos jornais: a imprensa compreendeu que deveria incentivar os festejos populares mais estruturados. Como já dito, a influência das brincadeiras entrudísticas nos préstitos das grandes sociedades acabou por gerar diversas manifestações de difícil classificação. Entretanto, as novas tendências da história intelectual de valorização da cultura popular fizeram com que, já na década de 1920, esses novos grupos começassem a ser reconhecidos e pelos jornais denominados "ranchos", "blocos" e "cordões".

O reconhecimento desses grupos populares acaba gerando uma divisão entre pequeno carnaval (dos ranchos, blocos e cordões) e grande carnaval (das grandes sociedades e dos corsos). É bom lembrar, entretanto, que a denominação "pequeno carnaval" tinha conotação positiva, associada à inocência e à pureza. Contudo, a repentina valorização das manifestações populares estruturadas não se dava apenas por conta das mudanças de paradigma da história intelectual - havia interesse em incentivar o turismo, e percebeu-se que o carnaval poderia ser forte atrativo, se bem aproveitado. Para isso, era necessário apresentar ao mundo uma festa organizada em grandes proporções e também elaborar uma imagem diferenciada, que a destacasse dos outros carnavais do mundo. A valorização dos grupos populares seguia esse segundo objetivo: era o que tornava a folia carioca alegre e espontânea e, portanto, "a melhor do mundo". ${ }^{5}$. Dessa maneira, a partir do final dos anos 1920, pela primeira vez o Estado passou a interferir diretamente na organização da festa, com destaque para as administrações dos prefeitos Prado Júnior (1926-1930) e Pedro Ernesto (1931-1934). ${ }^{6}$

O esforço de classificação e estruturação dos grupos populares, entretanto, não deve ser visto como uma medida tomada apenas de cima para baixo. Pelo contrário, os grupos se beneficiavam com essas medidas, já que ganhavam destaque na imprensa. Dessa maneira, eles próprios buscavam adaptar-se às categorias (ranchos, blocos e cordões) criadas, de modo que pudessem ser considerados membros do pequeno carnaval. Isso porque, mesmo com essa divisão entre pequeno e grande carnaval, algumas manifestações se mantinham à margem, ainda sen-

5. "O nosso Carnaval, incontestavelmente o meIhor do mundo, era até há pouco quase completamente ignorado nos paises estrangeiros, principalmente nos Estados Unidos; enquanto os de Nice, Veneza e outras cidades, inferiores a ele, sem a espontaneidade e alegria dos festejos do Carnaval carioca; obedecendo a programas e horários (...)" (O Imparcial, 22 de fevereiro de 1925).

6. Em 1932, Pedro Ernesto oficializará o carnaval carioca, deixando definitivamente nas mãos do Estado os encargos da organização da festa. do vistas como entrudo. Assim, é importante percebermos que a participação das massas não foi sempre "passiva", mas "ativa", visando também a interesses próprios.

A ascensão de Getúlio Vargas à Presidência da República em 1930 traria ainda mais força para a busca de uma identidade cultural para o Brasil. Mais ainda, a Era Vargas 
daria impulso à ideia de expressão única que pudesse representar todo o país, ou seja, que pudesse representar a "mistura de raças" que formava o Brasil. Nesse sentido, um gênero musical que vinha crescendo nas rádios começa a se destacar. Um ritmo que tinha suas origens nos morros e favelas cariocas, e que "resumia os vários sentimentos da alma brasileira" (FERREIRA, 2004, p.331): o samba.

Os grupos de samba de morro começaram a surgir já no final da década de 1910 em áreas como a Cidade Nova e os morros da Mangueira, do Salgueiro e de São Carlos. 0 gênero, como foi dito, representava a "mistura de raças" brasileiras, já que incluía ritmos africanos e gêneros musicais, como o maxixe. Em 1917 era gravado aquele que é considerado o primeiro samba: "Pelo telefone" iria ganhar as rádios e logo chamaria o interesse da elite intelectual do país para esse novo ritmo. Os intelectuais brasileiros passam então a se interessar pelo samba como expressão de nacionalidade, e os grupos de samba de morro ganham fama, suas músicas são tocadas nas rádios de todo país e até concursos são organizados por jornais.

Em momento de oficialização do carnaval (1932), os grupos de samba de morro já estavam extremamente fortalecidos e se tornariam o que conhecemos hoje como escolas de samba. O primeiro concurso oficial das escolas de samba foi realizado exatamente em 1932, na Praça Onze, local conhecido como o "reduto do samba". Com a organização do jornal Mundo Esportivo, o concurso contou com 19 grupos concorrentes, sendo sagrada campeã a Estação Primeira de Mangueira. A partir de então, como se sabe, as escolas de samba foram ganhando força e se multiplicando, sendo hoje provavelmente as entidades mais importantes do carnaval carioca ou até brasileiro.

Conforme visto, grande parte das mudanças do carnaval teve origem no Rio de Janeiro, desde o século XIX. Outras cidades brasileiras tentariam copiar a folia carioca, criando suas próprias sociedades carnavalescas, bailes de máscaras, blocos e escolas de samba. Entretanto, de acordo com os intelectuais brasileiros desse momento, o Rio de Janeiro seria a metonímia do Brasil, sua representação máxima, sendo, aliás, capital da República. É sempre bom lembrar, entretanto, que o modelo carioca não era copiado fielmente em outras cidades, mas sofria adaptações que fizeram com que o carnaval brasileiro se tornasse uma festa diversificada. O Rio de Janeiro, contudo, seria, reiteramos, por muito tempo a representação máxima do Brasil, podendo-se perceber, em alguns momentos, a equivalência entre os termos "carioca" e "carnavalesco". O carnaval seria considerado a maior manifestação carioca, a síntese do que seria "ser carioca", ou seja "ser brasileiro". "São Paulo dá café, Minas dá leite, e Vila Isabel dá samba", cantaria o sambista Noel Rosa em 1934.

A intelectualidade brasileira da virada do século XIX para o XX (incluindo nesse grupo romancistas, como José de Alencar, e folcloristas, como Melo Morais Filho, entre muitos outros) assumiu, portanto, o papel de "inventar" uma identidade nacional que representasse um Brasil civilizado e moderno. Nesse sentido, o Estado apoiava suas ações, por vezes de modo incisivo, por outras, apenas ideologicamente. Muitos desses intelectuais eram membros do aparelho estatal, diplomatas e estadistas. Para "forjar" a identi- 
dade nacional, era preciso agir também nas festas, que carregavam consigo a denúncia da realidade brasileira, o "barbarismo" tão temível. Ao buscar agir no carnaval, entretanto, esses intelectuais esbarraram em uma manifestação popular e espontânea, difícil de ser redefinida ou controlada. ${ }^{7}$ Seus projetos foram de encontro aos processos históricos, e acabaram dando novos rumos à folia (ainda que não exatamente os rumos desejados).

Em síntese, o que procuramos mostrar é que estudar o carnaval carioca (e brasileiro) se faz de extrema importância, visto que suas tensões acompanham as mudanças ocorridas nos paradigmas da intelectualidade brasileira e latino-americana. A história intelectual, portanto, mostra-se cada vez mais pertinente, porque justifica as mudanças ocorridas em diversos âmbitos, a folia incluída.

\section{REFERÊNCIAS BIBLIOGRAFICAS}

ANDERSON, Benedict. Comunidades imaginadas: reflexões sobre a origem e a difusão do nacionalismo. São Paulo: Companhia das Letras, 2008.

ANDREWS, George Reid. Uma transfusão de sangue melhor: o branqueamento, 18801930. In: América Afro-Latina (1800-2000). São Carlos, EdUFSCar, 2007.

CUNHA, Maria Clementina Pereira (org.). Carnavais e outras f(r)estas: ensaios de história social da cultura. Campinas: Ed. Unicamp, 2002.

. Ecos da folia: uma história social do carnaval carioca entre 1880 e 1920. São Paulo: Companhia das Letras, 2001.

FERREIRA, Felipe. Inventando carnavais: o surgimento do carnaval carioca no século XIX e outras questões carnavalescas. Rio de Janeiro: UFRJ, 2005.

. O Livro de Ouro do carnaval brasileiro. Rio de Janeiro: Ediouro, 2004.

GERSTLE, Gary. Raça e nação nos Estados Unidos, México e Cuba, 1880-1940. In: PAMPLONA, Marco; DOYLE, Don (orgs.). Nacionalismo no Novo Mundo. Rio de Janeiro: Record, 2008.

HALE, Charles. As ideias políticas e sociais na América Latina, 1870-1930. In: BETHELL, Leslie (org). História da América Latina - vol 4. São Paulo: Edusp, 2001.

MELO MORAIS FILHO, A.J. Festas e tradições populares do Brasil. Rio de Janeiro: Ediouro, 2005.

SANTOS, Luís Cláudio Villafañe G. O dia em que adiaram o carnaval: política externa e a construção do Brasil. São Paulo: Ed. Unesp, 2010.

SCHWARCZ, Lilia Moritz. O espetáculo das raças: cientistas, instituições e questão racial no Brasil 1870-1930. São Paulo: Companhia das Letras, 1993.

STEPAN, Nancy Leys. Identidades nacionais e transformações raciais. In: A hora da eugenia: raça, gênero e nação na América Latina. Rio de Janeiro: Ed. Fiocruz, 2005.

VASCONCELOS, José. La raza cósmica: misión de la raza iberoamericana. Madrid: Agencia Mundial de Librería, 1925.

Renata Bulcão Lassance Campos é graduanda em História da UFRJ.

BULCÃO, Renata. O carnaval carioca e a construção de uma identidade brasileira 